https://doi.org/10.18485/analiff.2017.29.1.1

\title{
O RAZVOJU METALINGVISTIČKE SVESTI - SVEST O REČI
}

\begin{abstract}
Svest o reči smatra se jednom od najbitnijih komponenata metalingvističke svesti. Osnovni cilj ovog rada je da predstavi različite dimenzije ove pojave - svest o reči kao jedinici jezika, svest o arbitrarnoj prirodi leksičkog znaka i razumevanje metalingvističkog koncepta „reč”, kao i da pruži pregled njihovog razvoja. Imajući u vidu rezultate novijih istraživanja koji ukazuju na bitnu ulogu koju usvajanje pismenosti ima na razvoj metalingvističke svesti, a time i na razvoj svesti o reči, posebno je razmotren odnos između razvoja svesti o reči i usvajanja pismenosti.
\end{abstract}

Ključne reči: metalingvističke kompetence, razvoj svesti o reči, usvajanje pismenosti, predškolci i deca ranog školskog uzrasta

\section{Uvod}

Osnovni cilj ovog rada je da ponudi pregled i sintezu postojećih istraživanja o razvoju svesti o reči, kao i o prirodi odnosa koji se uspostavlja između dva važna i međusobno uslovljena procesa - procesa razvoja metaleksičke svesti i procesa početnog usvajanja pismenosti. Svest o reči sastavna je komponenta metalingvističke svesti. Metalingvistička svest definiše se kao sposobnost govornika da jezik sagleda kao predmet, objekat svoga posmatranja, odnosno da ga „objektifikuje“ (Roth et al. 1996, 258), ili kao „sposobnost da se o jeziku razmišlja i manipuliše njegovim strukturnim obeležjima ... nasuprot tome da se samo upotrebljava kao sredstvo razumevanja i produkcije iskaza" (Tunmer \& Herriman 1984, 12). Posedovanje metalingvističke svesti omogućava da se pažnja sa značenja, odnosno sadržaja poruke preusmeri na formalni oblik njenog ispoljavanja, tj.

\footnotetext{
Katedra za opštu lingvistiku, Filološki fakultet, Studentski trg 3, 11000 Beograd, jasmina.moskovljevic@fil.bg.ac.rs.

** Ovaj rad nastao je u okviru projekta ,Identifikacija, merenje i razvoj kognitivnih i emocionalnih kompetencija važnih društvu orijentisanom na evropske integracije" (179018), koji finansira Ministarstvo prosvete i nauke Republike Srbije.
} 
na jezički izraz (Lundberg 1978; Owens 1996). Uz svest o reči, sastavnim komponentama metalingvističke svesti smatraju se još i fonološka, morfološka, sintaksička i pragmatička svest.

Fonološku svest Snow, Burns i Griffin (1998) definišu kao sposobnost usmeravanja pažnje na glasovna obeležja jezika (npr. sposobnost uočavanja da se u leksemama most i gost $\mathrm{u}$ inicijalnoj poziciji nalaze dve različite foneme $-/ \mathrm{m} / \mathrm{i} / \mathrm{g} /$ ). Razvijena morfološka svest podrazumeva postojanje predstave o morfološkoj strukturi reči i sposobnost da se njome manipuliše (Law \& Ghesquière 2017, 47), dok se sintaksička svest definiše kao sposobnost uočavanja sintaksičkih, formalnih obeležja rečenica (Tunmer \& Grieve 1984, 92). Ove tri komponente metalingvističke svesti prisutne su prvo na implicitnom (,epilingvističkom“) nivou da bi potom, postepeno, bile dostupne i na svesnom („metalingvističkom“) nivou (Reder et al. 2013, 687).

Za razliku od dosad pomenutih oblika metalingvističke svesti, koji su u prvom redu usmereni na sam jezik, pragmatička svest definiše se kao svest o relacijama koje se uspostavljaju između jezičkog sistema i spoljašnjeg sveta: ona podrazumeva da govornik shvata društveno determinisane norme jezičke upotrebe - zna, na primer, da je u određenim prilikama prikladno upotrebiti određene reči i izraze, dok u nekim drugim to nije, zna pravila odvijanja konverzacije, pozdravljanja, čestitanja, i sl. (Bates, 1976). Neki autori ovome pridodaju i metatekstualnu svest, za koju se smatra da je uključena u intencionalnu kontrolu organizovanja iskaza u veće lingvističke celine (Gombert 1997, 45), kao i mogućnost samoprocene stepena razumevanja teksta (Moskovljević Popović i Plut 2011). Razvoj metalingvističkih sposobnosti obično se dovodi i u vezu sa promenama u opštem načinu funkcionisanja kognitivnog sistema do koga dolazi tokom perioda „srednjeg detinjstava“ (uzrast 6-9 godina) i rane adolescencije (10-14 godina). Takođe se smatra da je razvijenost bar nekih aspekata metalingvističke svesti, u prvom redu fonološke, nužan preduslov za uspešno usvajanje početnog čitanja i pisanja.

\section{Razvoj svesti o reči}

Svest o reči, ili metaleksička svest, operacionalno se definiše kao sposobnost izdvajanja pojedinačnih leksema iz kontinuiranog govornog toka, odnosno kao sposobnost razlikovanja oznake i označenog (Kurvers et al. 2006, 46). Smatra se da nije reč o jedinstvenom fenomenu i da potpuno ra- 
zvijena metaleksička svest obuhvata sledeće tri komponente: (1) svest o reči kao jedinici jezika, odnosno svest o tome da je govorni tok moguće podeliti na manje jedinice; (2) svest o arbitrarnoj prirodi jezičkog znaka, tj. svest o tome da su referent i ono što on označava dva posebna entiteta; (3) razumevanje metalingvističkog termina ,reč”. Ova tri aspekta svesti o reči ne stiču se u isto vreme i imaju različit razvojni tok (Bowey \& Tunmer 1984, 73).

\subsection{Svest o reči kao jedinici jezika}

U najvećem broju istraživanja koja su se bavila razvojem svesti o reči kao jedinici jezika od dece se tražilo da iz auditivno prezentovanog stimulusa, čija je priroda varirala, izdvoje reči, odnosno „male delove” onoga što čuju. Na taj način se obezbeđivalo da čak i ona deca koja ne poznaju značenje termina ,reč”, ili ga shvataju na način koji je drugačiji od načina na koji se on koristi u govoru odraslih, mogu da razumeju i izvrše zadatak - ,dete može biti u stanju da podeli govornu sekvencu na reči i na taj način pokaže da poseduje svest o reči kao jedinci jezika, čak i ako ne poznaje značenje terimina ,reč” (Bowey \& Tunmer ibid., 74). Pionir u ovoj vrsti istraživanja bila je Sofija Nikolajevna Karpova. Ona je još početkom druge polovine prošlog veka utvrdila da deca uzrasta 3-7 godina nisu u stanju da podele rečenicu na reči, ili bar ne da to učine na način kako to čine odrasli govornici. Kada bi dobila zadatak da izbroje reči u rečenici, najmlađa deca davala su odgovor da se radi o jednoj celini. Tako je, na primer, dečak koji je odgovorio da se rečenica Dečak se smeje sastoji od jedne reči, svoj odgovor objasnio rekavši da je to jedna reč ,jer se samo jedan dečak smeje“. Nešto starija deca su rečenicu najčešće delila u dve celine - subjekat i predikat. Tek na uzrastu od oko 6-7 godina deca su bila u stanju da izdvoje pojedinačne reči iz rečenice, ali su i tada najčešće propuštala da izdvoje funkcionalne reči (predloge i veznike, npr.) kao zasebne leksičke jedinice (Karpova 1966, navedeno prema Kurvers et al., ibid. i Onderdelinden et al., 2009, 36).

Rezultati istraživanja izvršenih u narednih tridesetak godina dodatno su učvrstili inicijalne nalaze iako su pri njihovoj realizaciji korišćene drugačije metode, za koje se verovalo da su bolje prilagođene uzrastu ispitivane dece (Holden \& McGinitie 1972, Papandropoulou \& Sinclair 1974, Berthoud-Papandropoulou 1978). Uvek se iznova potvrđivalo da je zadatak posebno težak, a rezultati loši, kada je iz govornog niza treba-

lo izdvojiti funkcionalne reči. Dok većina dece uzrasta 6-7 godina nije 
imala posebnih problema pri izdvajanju sadržajnih reči (imenica, glagola, prideva i priloga) iz rečenice, situacija je bila potpuno drugačija kada je trebalo izdvojiti funktore (članove, predloge, veznike, pomoćne glagole i sl.). Takvi rezultati naveli su istraživače da zaključe da za decu ovog uzrasta funkcionalne leksičke jedinice nemaju status punopravnih leksema. Da bi se ovakvi nalazi objasnili, ukazivalo se na osnovnu razliku koja postoji između otvorenih (sadržajnih) i zatvorenih (funkcionalnih) klasa reči, na osnovu koje se i vrši podela na ove dve klase leksema. Dok su članovi otvorenih klasa reči nosioci samostalnih, konkretizovanih značenja, pripadnici zatvorenih klasa svoje značenje dobijaju tek u spoju sa drugim rečima, odnosno tek u širem jezičkom kontekstu. Otuda su njihova značenja u mnogo većoj meri apstraktna i za decu predškolskog i ranog školskog uzrasta teško spoznatljiva i uočljiva. A kad se jezička jedinica ne uočava, onda je jasno da neće biti ni izdvojena iz govornog niza. Do bitnog preokreta dolazi tek na uzrastu 7-8 godina, upravo u periodu tokom koga se odvija početno usvajanje čitanja i pisanja.

Dodatni nalazi iz istraživanja posvećenih razvoju svesti o reči kao jedinci jezika pokazali su da deca iz govornog toka mnogo lakše izdvajaju dvosložne i trosložne nego jednosložne reči. Ovakvi rezultati objašnjavaju se činjenicom da se jednosložne reči pri izgovoru mnogo češće stapaju sa prethodnom ili rečju koja im sledi, pa su samim tim i teže uočljive, kao i time da su, za razliku od dvosložnih i trosložnih, jednosložne reči vrlo često neakcentovane (Onderdelinden et al., ibid.).

Suprotno od rezultata dobijenih u dosad prikazanim istraživanjima koji su u velikoj meri homogeni i navode na iste zaključke, rezultati (relativno) novijih ispitivanja razvoja svesti o reči kao jedinci jezika ne samo da su znatno drugačiji, već su u izvesnoj meri i kontraverzni. Naime, Karmiloff-Smith et al. (1996, 200-201) su u seriji od tri eksperimenta primenile novu istraživačku tehniku (tzv. ,on-line“ metodologiju) prilikom ispitivanja sposobnosti dece da izdvoje reči iz govornog toka - smatrale su da primena ove metode omogućava da deca pod znatno prirodnijim uslovima iskažu svoju sposobnost za segmentaciju rečenica. „On-line“ procedura podrazumeva da narator tokom čitanja priče zastane na unapred određenim mestima i od deteta traži da ponovi ,poslednju reč“ ili ,poslednju stvar" koju je čulo. Reči koje je trebalo ponoviti birane se tako da je među njima bio podjednak broj onih koje se svrstavaju u klasu sadržajnih (punoznačnih) i onih koje pripadaju klasi funkcionalnih reči. Ispitanici su bila monolingvalna deca uzrasta 4-5 godina kojima je engleski maternji jezik. 
Rezultati do kojih su Karmiloff-Smith et al. došle izrazito se razlikuju od svih dotadašnjih: kada je reč o leksemama koje pripadaju otvorenoj klasi reči, četvorogodišnjaci su ih uspešno izdvojili u 76.82\%, a petogodišnjaci u 97.14\% slučajeva, dok su u slučaju leksema koje pripadaju zatvorenoj klasi reči četvorogodišnjaci bili uspešni u 73.70\%, a petogodišnjaci u 95.31\% slučajeva. Istovremeno, analiza rezultata za svako pojedinačno dete pokazala je da je (samo) 14 od 24, odnosno 58.3\% četvorogodišnjaka dalo tačne odgovore u 80\% (ili preko $80 \%$ ) slučajeva, dok je to učinilo 23 od 24 , odnosno $95.8 \%$ petogodišnjaka. Na osnovu ovakvih rezultata, Karmiloff-Smith et al. izvele su sledeće zaključke: 1. razvoj svesti o reči kao jedinici jezika počinje mnogo ranije nego što se to smatralo; 2 . ovaj proces izrazito je gradualne prirode $\mathrm{i}$ otuda je pitanje ,kad tačno dete stiče metaleksičku svest“" pogrešno, kao i stav da se svest o reči pojavljuje iznenada na uzrastu od oko sedam godina; 3 . uzrast od četiri godine označava period tranzicije - mlađa deca poseduju samo zametak koncepta reči, dok su ga starija već stekla; 4. deca već na uzrastu od pet godina imaju punu svest o tome da su i članovi zatvorenih klasa reči takođe reči (ibid., 213-214).

Želeći da provere ove nalaze i zaključke, kao i da utvrde da li su oni validni i kada je reč o drugim jezicima, Kurvers i Uri (2006) izvršile se istraživanje u kome su u potpunosti preuzele metodologiju koju su primenile Karmiloff-Smith et al., osim što su u njihovom ispitivanju učestvovala monolingvalna deca koja usvajaju holandski i norveški, a ne engleski jezik. Rezultati do kojih su došle mnogo su više u skladu sa rezultatima ranijih istraživanja razvoja svesti o reči, a značajno se razlikuju od rezultata Karmiloff-Smith et al. Četvorogodišnjaci koji usvajaju holandski jezik uspešno su identifikovali samo $24.6 \%$ leksema koje pripadaju otvorenoj klasi reči i isto toliko leksema koje se svrstavaju u zatvorene klase reči. Ni petogodišnjaci nisu bili uspešniji - tačno su izdvojili 24.2\% sadržajnih reči i 26.3\% funkcionalnih reči. Deca koja usvajaju norveški jezik bila su nešto uspešnija, ali su ovi rezultati i dalje višestruko lošiji nego oni koje su postigla deca u istraživanju Karmiloff-Smith et al:: četvorogodišnjaci su tačno identifikovali 29.5\% leksema iz otvorenih klasa reči i 27.8\% leksema iz kategorije funktora, dok su petogodišnjaci uspešno izdvojili $29.3 \%$ sadržajnih i $26.4 \%$ funkcionalnih leksema. Takođe, nijedno četvorogodišnje dete ni iz holandskog ni iz norveškog dela uzorka nije doseglo prag od $80 \%$ tačnih odgovora, dok je među petogodišnjacima bilo jedno takvo dete $(\sim 3 \%)$ među decom koja usvajaju holandski i dvoje $(\sim 8 \%)$ među decom koja usvajaju norveški jezik. 
Razlike u rezultatima ova dva istraživanja toliko su velike da je jasno da objašnjenje mora da uputi na neki dodatni, spoljašnji faktor čiji je uticaj na razvoj svesti o reči posebno značajan. Kurvers i Uri (ibid., 362363) su u interpretaciji i poređenju rezultata svog i istraživanja Karmiloff-Smith et al. ukazale na različite pristupe pismenosti, kao i na razlike u pedgoškoj praksi kada je o ranom opismenjavanju reč kao na mogući presudni faktor uticaja na razvoj svesti o reči. Naime, dok se deca u Velikoj Britaniji znatno ranije uključuju u raznovrsne aktivnosti koje podržavaju razvoj pismenosti, to nije slučaj sa decom istog uzrasta u Holandiji i Norveškoj koja prva iskustva sa pisanim formama jezika stiču nešto docnije. Iako ovo objašnjenje svakako može da bar delimično ukaže kako je došlo do ovako velike razlike u rezultatima u ovim (a i brojnim drugim) sličnim istraživanjima, ono istovremeno otvara i čitav niz novih pitanja o prirodi odnosa između razvoja svesti o reči kao jedinci jezika i pismenosti - šta dolazi prvo, a šta sledi, u kom smeru teče uticaj (od postojanja svesti o reči ka uspešnom ovladavanju pismenošću, ili obrnuto) i može li se, na koji način i kojim aktivnostima podržati i pospešiti razvoj svesti o reči?

\subsection{Svest o arbitrarnoj prirodi leksičkog znaka}

(razlikovanje oznake i označenog)

Rana ispitivanja sposobnosti dece da razlikuju oznaku i označeno vršili su još Pijaže i Vigotski dvadesetih i tridesetih godina prošlog veka. U pokušaju da utvrdi uzrast na kome je dete sposobno da napravi jasnu distinkciju između referenta i reči koja ga označava, Pijaže govori o tri različite faze razvoja: tokom prve faze (sve do uzrasta 7-8 godina), deca ne prave nikakvu razliku između reči i onoga što ona označava, ona čak ne mogu ni da razumeju problem. Tokom druge faze (7-11 godina) deca shvataju da problem postoji, ali nisu u stanju da ga u potpunosti reše, niti da ga na sistematičan način sagledaju. Tek u trećoj fazi (posle 10. ili 11. godine) dete uspešno rešava problem (Piaget 1951, 56). Pijaže svaku od faza ilustruje odgovorima koje deca daju na pitanje „Da li reči imaju snagu?“" Za prvu fazu, između ostalih, navodi sledeći primer: „Bourg (6): Imaju li reči snagu? - Ne, ... da. — Reci mi neku jaku reč. - Tata, zato što je on tata $i$ zato što je jak." Druga faza, koju Pijaže označava kao paradoksalnu zato što sa jedne strane dete shvata problem i donekle ima uvid da je reč nešto različito od onoga što označava, ali sa druge ovo razlikovanje nije 
dovoljno iskristalisano da bi mu omogućilo da izbegne zamku koju predstavlja pitanje, ilustrovana je sledećim primerom: „Aud (8;8): Imaju li reči snagu? - Ne, reči nisu ništa. One nisu jake, ne možeš ništa da staviš na njih. - Reci mi neku reč. - Zavesa. Ona nije jaka jer ako nešto staviš na nju, ona se cepa. Reči nisu jake zato što ne možeš da staviš ništa na njih. Reč je kad govoriš. Ako nešto staviš na reč „papir“ ona će da se pocepa. ... - Reci mi još jednu reč. - Stalak za kišobrane. On je jak zato što možeš da staviš kišobrane u njega. — Da li kišobrane stavljaš u reč? — Ne. - Da li je reč jaka? - Ne. — Zašto reč „zavesa“ nije jaka? — Zato što se lako cepa." Pijaže skreće pažnju da je iz Audovih kontradiktornih odgovora očito da on još uvek ima poteškoća da razlikuje oznaku od označenog, kao i misao od stvari o kojoj razmišlja. Tek u trećoj fazi dete je sposobno da napravi jasnu razliku između oznake $\mathrm{i}$ označenog i izbegne da upadne $\mathrm{u}$ zamku koju pitanje predstavlja: „Tie (10;10): Imaju li reči snagu? — Zavisi od reči. — Koja je reč jaka? — Reč ,, boks “... uf, ne... ne, reči nemaju snagu, nikakvu (smejući se). — A zašto si prvo mislio da imaju? - Pogrešio sam. Mislio sam da reč udara" (Piaget ibid., 57-59).

Ova nemogućnost da se sve do uzrasta od oko deset godina oznaka jasno razluči od označenog, kao i korespondentna nemogućnost da se misao odvoji od entiteta o kome se misli, predstavljaju značajnu karakteristiku dečjeg mišljenja na tom uzrastu, koju je Pijaže označio terminom nominalni realizam. ${ }^{1}$

I Vigotski se bavio sposobnošću dece da razlikuju oznaku i označeno. U nizu ispitivanja koje je izvršio, a čiji su učesnici bila mahom deca predškolskog uzrasta, i on je utvrdio da je ime predmeta na ovom uzrastu neraskidivo povezano sa njegovim svojstvima: „Krava se zove krava zato

1 Treba, međutim, imati u vidu da neki savremeni autori negiraju postojanje nominalnog realizma i da ga smatraju epifenomenom (v. npr., Ephratt 1991). S druge strane, savim je moguće da deca i dalje prolaze kroz fazu nominalnog realizma, ali da se zbog sve ranijeg ulaska u formalni obrazovni sistem i velikog uticaja obilja informacija kojem su izložena, nominalni realizam ili prevazilazi na mnogo mlađem uzrastu nego ranije, ili samo biva „zamaskiran“ pod uticajem različitih činjenica i informacija kojima je dete obasuto i koje naprosto reprodukuje jer ih smatra tačnim pošto su mu saopštene od strane autoriteta - odrasle osobe. Sledeći primer bi ilustrovao ovu drugu mogućnost: četvorogodišnje dete je u vrtiću naučilo da Deda Mraz ne postoji i na sva pitanja o njemu odgovara da on ne postoji. S druge strane, posle par dana, isto dete predaje roditeljima pismo (skup crteža i različitih ispisa koji predstavljaju njegove želje) i traži od njih da ga zapakuju u kovertu, nalepe marku, i pošalju Deda Mrazu na Severni pol. 
što ima rogove, tele zato što su mu rogovi još mali, konj zato što nema rogove, pas zato što nema rogove i što je mali, a automobil se zove automobil zato što uopšte nije životinja." (Vigotski 1996, 235). Na pitanje da li se ime jednog predmeta može zameniti drugim, deca tog uzrasta odgovaraju da je to apsolutno nemoguće i objašnjavaju da se krava ne može nazvati mastilom, a mastilo kravom zato što se mastilom piše, a krava daje mleko. Rečima Vigotskog: „Prenošenje imena kao da znači i prenošenje svojstava jedne stvari na drugu, toliko su tesno i nerazdvojno povezana svojstva predmeta i njegov naziv. ... Vidimo kako je teško detetu da odvoji ime stvari od njenih svojstava i kako svojstva stvari prilikom prenošenja prate ime, kao imovina vlasnika“" (ibid.).

Novija ispitivanja potvrdila su, proširila i produbila ranija saznanja o razvoju sposobnosti za razlikovanje oznake od označenog. U istraživanju sprovedenom sedamdesetih godina prošlog veka Papandropoulou i Sinclair (1974, 243-244) tražile su od svojih ispitanika uzrasta od 4;5 do 10;10 da im navedu primere za dugačke, kratke i teške reči, kao i za reč koju su oni sami izmislili. Rezultati ovog istraživanja pokazali su da deca uzrasta 4;56;0 ne prave nikakvu razliku između reči i stvari, odnosno da su oznaka i označeno za njih neodvojivi. Kao primere za dugu reč navodila su ili velike objekte, ili radnje koje dugo traju i/ili se prostiru na veliku udaljenost: stolica (zato što ima dugačke noge), voz (zato što putuje daleko i mnogo ljudi je u njemu), dečak (koji trči, i trči i trči, najbrže što može). Kao kratke, navođene su reči koje označavaju objekte malih dimenzija: bela rada (zato što je mala), a kao teške one koje označavaju neprijatne radnje ili predmete: $z u b$ (zato što ispada napolje), neko ko vadi ključ iz vrata (zato što je to teško), raspremanje igračaka. Deca ovog uzrasta takođe su objašnjavala da je nešto reč upravo zato što ima određeno svojstvo: ,jagoda je reč zato što raste u bašti“, a „olovka zato što se njome piše“". Kada se od njih tražilo da navedu reč koju su sami smislili, ili su navodili prvo što im padne na pamet, ili nemoguće, nerealne situacije: riba u kugli bez vode, automobil koji pliva i leti i sl. (ibid.). Na uzrastu od 5 do 7 godina pojavljuju se istovremeno dve različite koncepcije odnosa između oznake i označenog. Obema je zajedničko da se reči više ne izjednačuju sa realnošću, već samo korespondiraju sa njom, mada i dalje postoji vrlo čvrsta veza između reči i realnosti koju ona reprezentuje. Shodno tome, reči su ili ono što se kaže o nečemu, ili ono što se upotrebljava da bi se nešto imenovalo. U prvom slučaju, deca kao primere za reč navode čitave rečenice (reč = komentar), 
u drugom navode reči, ali samo sadržajne, odnosno reči iz otvorenih klasa (reč = etiketa). Primer za reč $=$ komentar, odnosno reč $=$ rečenica ilustruje sledeći dijalog između deteta i istraživača: „The nije reč zato što ti treba još nešto, truck ti treba. Ali kad eksperimentator pita da li je ,the truck“" reč, dete $(5 ; 4)$ nastavlja ' $\mathrm{Ne}$, the truck, to nije dovoljno, za reč ti trebaju dve stvari, recimo, the truck ... it goes' (ibid., 245). Primer za reč = etiketa je odgovor deteta $(6 ; 2)$ koje na zahtev da kaže reč nabraja niz imenica: kola, kuća, policajac,crkva, aligator, a na pitanje da kaže zašto su to reči, objašnjava: ,... zato što je to pravo, to su prava imena...“, tj., to postoji (ibid.) Članovi, predlozi i druge lekseme iz zatvorenih klasa reči još uvek ne bivaju prepoznate kao prave reči - deca objašnjavaju da to nisu reči jer su kratke, imaju mali broj slova i ne postoje, dok je âne (fr. magarac), iako je kratka ipak reč jer âne (magarac) postoji. Kada se od dece koja su na ovom stadijumu shvatanja odnosa oznaka - označeno traži da navedu dugu reč, tipični odgovori su: „Zmija koja živi u šumi““ (reč = komentar), ili: ,lokomotiva“ (reč = etiketa) - u oba slučaja reč je o svojevrsnom kompromisu - imenička sintagma sa relativnom rečenicom jeste duga, kao što i njen upravni član referira na biće značajne dužine, a i drugi navedeni primer je po obliku duga, petosložna reč koja takođe označava dugačak objekat. U istraživanju Papandropoulou i Sinclair tek su deca uzrasta od 8 do 10 godina pokazala da su u stanju da naprave jasnu distinkciju između reči i entiteta koji reč označava, odnosno između oznake i označenog.

Slični su i rezultati ispitivanja u kome je proveravana sposobnost dece da uspostave vezu između izgovorenog i napisanog, odnosno između fonemske i grafemske slike reči. Lundberg and Torneus (1978) su izvele istraživanje u kome su ispitanicima prvo izgovarale parove reči, a potom im pokazivale te iste reči ispisane na komadu papira sa zahtevom da prepoznaju koja je reč gde zapisana. Njihovi rezultati potvrdili su da sedmogodišnjaci ne shvataju arbitrarnost odnosa između oblika reči i onoga što ona označava. Ispitanici su po pravilu birali onu ispisanu reč koja im se činila odgovarajućom po nekom semantičkom, a ne formalnom kriterijumu. Tako bi, kada bi im bile pokazane ispisane reči „,tree“ $i$,tennis racket", pokazivali na „tennis racket" kao oznaku za „tree“ objašnjavajući to time da je drvo veliko, mnogo veće od teniskog reketa, te da stoga i kad se napiše mora biti veće, odnosno duže (Lundberg and Torneus, ibid.).

U poslednjih 15-20 godina se, u sklopu istraživanja teorije uma, dečije shvatanje odnosa oznaka - označeno dovodi u vezu sa razvojem spo- 
sobnosti za reprezentaciju kako sopstvenih, tako i tuđih znanja i verovanja (Kamawar \& Olson 1999, Apperly \& Robinson 2002). Uspostavljanje ove veze između lingvističkih i drugih tipova reprezentacija otvara novu perspektivu i fokus interesovanja pomera ka praćenju pojave i razvoja reprezentacija u okviru različitih domena, uključujući i lingvistički, i traženju zajedničkih obeležja koja karakterišu i determinišu ove procese.

\subsection{Razumevanje metalingvističkog termina „reč“}

Ovaj aspekt svesti o reči stiče se najkasnije, a istovremeno je i najnejasnije da li ga uopšte treba uzimati u obzir kada se istražuje razvoj koncepta reči. Naime, s obzirom na teškoće sa kojima se susreću i sami lingvisti prilikom određivanja obima i sadržaja ovog pojma, kao i na neslaganja koja među njima postoje, pitanje je u kolikoj meri je razumevanje termina „reč“ rezultat spontanog formiranja i razvoja metalingvističkih kompetencija kod deteta, a koliko je posledica njegovog uključivanja u proces formalnog obrazovanja u okviru koga mu se, između ostalog, nudi već oformljena, gotova definicija i ovog termina. ${ }^{2}$

Još je Pijaže utvrdio da je koncept reči težak i nejasan mlađoj deci sve do uzrasta $7-8$ godina, za razliku od koncepta imena, koji im je, naprotiv, sasvim jasan (Piaget ibid., 61). Kada je Francis (1973) tražila od dece da joj kažu reč „,bilo koju reč koju znate“, samo 44\% njenih subjekata uzrasta 5;9 bilo je u stanju da pruži tačan odgovor, dok je 26\% odgovorilo navodeći neko vlastito ime ili naziv broja, što je, po Francis, ukazivalo da poseduju bar delimično razumevanje termina ,reč“‘. Na uzrastu 7;3 broj dece koja navode reč koja nije vlastito ime ili neki drugi naziv narastao je na $92 \%$. U ispitivanjima koja su sprovele Berthoud-Papandropoulou (1978) i Papandropoulou i Sinclair (1974) od dece različitog uzrasta tražilo se da definišu reč tako što su im postavljana sledeća dva pitanja: „Šta je u stvari reč?“ i „Kako znaš da je nešto reč?"“. Deca uzrasta 4;5 - 6 godina nudila su ,definicije“ iz kojih je bilo uočljivo da za njih reči nemaju samostalnu egzistenciju nezavisnu od onoga što označavaju (v. odeljak 2.2 i Papandropoulou and Sinclair, ibid., 244). Na uzrastu između osam i deset godina, kada su već bila uključena u obrazovni sistem, deca su davala definicje koje su ukazivale na snažan uticaj formalnog obrazovanja - odgovori su bili su izrazito jednoobrazni i većina dece koristila je identične, gotovo formulaičke reči i izraze prilikom defini-

$2 \quad$ Up. Bowey \& Tunmer 1984: 74 i dalje. 
sanja, kao što ilustruje i sledeća definicija deteta uzrasta 8;3: „Reč je nešto što znači nešto i piše se slovima“" (ibid., 247).

Rezultati ispitivanja koje su sproveli Downing i Oliver (1974) pokazali su da i deca uzrasta $7-8$ godina još uvek mešaju reči sa slogovima i pojedinačnim glasovima iako, u najvećem broju slučajeva, do tada već razlikuju pojedinačne reči od sintagmi i rečenica.

Ukupno uzevši, rezultati dosadašnjih ispitivanja pokazuju da se sposobnost razumevanja i definisanja metalingvističkog termina „reč“ razvija tokom dužeg niza godina, sve do perioda rane adolescencije. Iako ovo na prvi pogled može izgledati neobično i kontraintuitivno s obzirom da i vrlo mala deca koriste leksemu ,reč“ i pokazuju da je bar delimično razumeju, ne treba gubiti iz vida da se razumevanje apstraktnih koncepata, kao i sposobnost njihovog definisanja, uključujući i sposobnost definisanja metalingvističkih termina, razvija tek po ulasku u stadijum formalnih operacija i dostizanju odgovarajućeg nivoa razvoja apstraktnog mišljenja ( $\mathrm{tj}$. u periodu između dvanaeste i petnaeste godine).

\subsection{Razvoj svesti o reči kod dece koja usvajaju srpski jezik}

U jedinom eksperimentalnom istraživanju stepena razvoja svesti o reči koje je izvedeno na uzorku dece koja usvajaju srpski kao maternji jezik, ispitivane su istovremeno dve dimenzije razvoja svesti o reči: (1) svest o reči kao jedinici jezika i (2) svest o tome da je priroda lingvističkog znaka arbitrarna. Druga dimenzija ispitivana je preko dva različita aspekta i u dva različita zadatka: prisustvo vs. odsustvo nominalnog realizma i prisustvo vs. odsustvo sposobnosti da se napravi razlika između formalnih karakteristika reči (njenog oblika) i značenja reči. Ispitano je ukupno sto dece kasnog predškolskog uzrasta (prosečan uzrast: 6;10), iz gradske sredine i srednjeg socioekonomskog statusa (Kodžopeljić 1997). ${ }^{3}$ Analiza dobijenih rezultata pokazala je da se i pre usvajanja pisanog jezika pojavljuju oba ispitivana oblika svesti o rečima, ali u različitoj meri. Tako je svest o reči kao jedinici jezika bila prisutna kod $77 \%$ ispitivane dece,

3 J. Kodžopeljić (ibid., 234) smatra da su prisustvo/odsustvo nominalnog realizma i razlikovanje oznake od označenog dve različite dimenzije svesti o reči i samo prvu svrstava pod „svest o arbitrarnosti veze imena i objekta“. Ovo svakako nije tačno - upravo se odsustvo bilo kakvog oblika predeterminisane veze između oznake i označenog smatra esencijalnim delom učenja o arbitrarnosti jezičkog znaka (Sosir, 1989.) 
a razliku između formalnih odlika reči (njene zvučne slike) i njenog značenja, odnosno razliku između oznake i označenog pravilo je $81 \%$ dece. Nasuprot tome, samo kod $17 \%$ dece uočeno je odsustvo nominalnog realizma. Uz to, samo 8\% dece ovog uzrasta bilo je u stanju da i funkcionalne reči izdvoji i prepozna kao reči, kao što su i kod samo 15\% ispitanika bila zastupljena sva tri aspekta svesti o reči (ibid., 235-236).

Drugi deo ovog istraživanja izveden je sa istim ispitanicima osam meseci kasnije kada su deca već završila sa početnom obukom u čitanju. To prilikom proveren je njihov uspeh u čitanju i razumevanju teksta i dobijeni rezultati upoređeni su sa rezultatima iz prethodne faze istraživanja. $\mathrm{Na}$ osnovu izvršenih analiza i poređenja ustanovljeno je da postojanje svesti o reči kao jedinici jezika ima značajnog uticaja na početno usvajanje čitanja, odnosno da statistički značajno utiče kako na brzinu čitanja, tako i na razumevanje pročitanog. Slični rezultati dobijeni su i kada je u pitanju postojanje svesti o arbitrarnoj prirodi jezičkog znaka, odnosno o distinkciji oznaka označeno: grupa ispitanika koja je bila uspešna u proceni dužine reči (i nije je izjednačavala, već jasno odvajala od dužine referenta/entiteta koga reč označava) postigla je statistički značajno bolje rezultate na svim varijablama kojima se merio uspeh u čitanju (ibid., 238-239). Nasuprot tome, prisustvo, odnosno odsustvo nominalnog realizma u dečjem načinu razmišljanja nije imalo nikakvog uticaja na uspeh u početnom opismenjavanju.

Pored toga što svakako zaslužuju pažnju jer su jedini koji se odnose na razvoj svesti o reči kod dece koja usvajaju srpski jezik, ovi rezultati značajni su i na širem planu - oni nedvosmisleno pokazuju da razvoj svesti o reči ima isti tok kod dece koja usvajaju različite jezike, iz čega sledi da je reč o dubljem, bazičnijem kognitivnom i lingvističkom procesu na koji formalne i konstrukcione specifičnosti pojedinih jezika nemaju uticaja. Uz to, ovi rezultati potvrđuju ranije nalaze da se različiti aspekti dimenzije arbitrarnosti jezičkog znaka međusobno razlikuju po uzrastu usvajanja.

\section{Razvoj svesti o reči i usvajanje pismenosti}

O odnosu razvoja svesti o reči (i drugih metalingvističkih kompetencija) i usvajanja pismenosti postoje dva suprotstavljena stava. Dok jedna grupa autora smatra da je određeni nivo razvijenosti metalingvističkih kompetencija nužan preduslov za usvajanje pismenosti i da značajno utiče na 
uspeh u čitanju i razumevanju teksta (npr. Tunmer \& Bowey 1984, Edwards and Kirkpatrick 1999, Sharpe \& Zelazo 2002), drugi zastupaju stav da je ovladavanje pisanim formama jezika primarno i da ima presudan značaj kako za razvoj metalingvističkih sposobnosti uopšte, tako i za razvoj svesti o reči (npr. Vigotski 1996, Homer \& Olson, 1999, Ravid \& Tolchinsky 2002).

Razmatrajući uticaj metalingvističkih kompetencija Bowey i Tunmer navode kako dete da bi naučilo da čita mora biti u stanju da obrati pažnju na strukturna obeležja govora (jedine forme jezika sa kojom je do tada bilo u kontaktu). Metalingvistička sposobnost objektifikacije jazika otuda je važan preduslov za usvajanje čitanja pošto bez posedovanja ove sposobnosti dete ne bi bilo u stanju da otkrije ona obeležja govornog jezika koja su od centralnog značaja za uspostavljanje odgovarajućih odnosa korespondentnosti između usmenog i pisanog jezika. A postojanje svesti o reči, po ovim autorima, od krucijalnog je značaja jer se govor mora prvo na nivou reči (a tek potom na fonemsko-grafemskom nivou) dovesti u vezu sa pisanim jezičkim izrazom (ibid., 154-156). Edwards i Kirkpatrick (ibid., 326) smatraju da će podučavanje dece pismenosti biti smisleno i dati rezultate samo ukoliko načini i tehnike rada sa decom budu usklađene sa trenutnim stepenom njihovog metaleksičkog i metajezičkog razvoja.

Vigotski je bio prvi koji je ukazao na značaj ovladavanja pismenošću za razvoj metalingvističkih kompetencija: „U pisanom govoru dete mora delovati voljno, pisani govor je voljniji od usmenog. To se provlači kao lajtmotiv kroz ceo pisani govor. Već glasovna struktura reči, koja se u usmenom govoru izgovara automatski, bez raščlanjavanja na pojedine delove, zahteva prilikom pisanja sricanje, raščlanjavanje. Izgovarajući ma koju reč, dete nije svesno koje glasove izgovara i ne obavlja nikakve namerne radnje prilikom izgovaranja svakog pojedinačnog glasa. U pisanom govoru, naprotiv, ono mora da dovede do svesti glasovnu strukturu reči, da je raščlani i voljno reprodukuje u pismenima“" (Vigotski 1996: 180).

Homer i Olson (ibid.) takođe zastupaju stav da pismenost ima presudan uticaj na razvoj metalingvističke svesti. Razvijajući ideje Vigotskog, oni smatraju da pisanje pruža model koji se koristi i pri analizi i segmentaciji govora. Kako bi svoju hipotezu proverili, izveli su dva eksperimenta čiji su rezultati pokazali da dete i pre nego što se opismeni shvata reprezentacionu prirodu pisanja, kao i da se dečije razumevanja reči kao jedinice jezika može predvideti na osnovu postojanja svesti o tome da je reč izdvojena celina unutar pisanog teksta (,,reč je ono što imamo između dve beline“). 
Razmotrivši različite postulate o odnosu metalingvističkog i metaleksičkog razvoja i usvajanja pismenosti, Ravid i Tolchinsky zastupaju donekle kompromisan stav. Naime, iako ističu da konvencije pisanog jezika promovišu metalingvističke kompetencije u različitim domenima (fonološkom, leksičkom, sintaksičkom, pragmatičkom), one navode i da je razvoj lingvističke svesti rezultat zajedničkog delovanja kognitivnog i jezičkog razvoja, jezičkog iskustva i formalnog obrazovanja. A sposobnost da se reprezentuje, vrednuje i voljno manipuliše jezičkim oblikom i značenjem je, po njihovom mišljenju, rezultat složenog, objedinjenog i koherentnog skupa lingvističkih znanja koje može posedovati samo odrasli pismeni pojedinac (ibid., 430-432).

\section{Zaključak}

Pregled istraživanja o razvoju svesti o reči pokazuje da različite dimenzije ove sposobnosti imaju različite razvojne tokove: dok se neki njeni aspekti pojavljuju, bar u inicijalnom obliku, relativno rano (oko četvrte godine), usvajanje drugih proteže se sve do perioda rane adolescencije. Iako veza između pojedinih dimenzija (a posebno odnos između prisustva/odsustva nominalnog realizma i drugih dimenzija svesti o reči) još uvek nije dovoljno ni teorijski ni empirijski razjašnjena, rezultati brojnih istraživanja ukazuju da se svest o reči kao jedinici jezika formira prva i da ona čini osnovu za ovladavanje drugim dimenzijama svesti o reči. Svest o arbitrarnoj prirodi odnosa između oznake i označenog usvaja se nešto kasnije, a razumevanje metalingvističkog koncepta „reč“ tek sa razvojem apstraktnog mišljenja.

Kada je o razvoju svesti o reči i usvajanju pismenosti reč, još uvek je u toku debata između onih autora koji smatraju da je posedovanje određenih aspekata svesti o reči nužan preduslov za uspešno opismenjavanje i onih koji smatraju da tek ovladavanje pisanim formama jezika omogućava pun razvoj ne samo svesti o reči, već i ostalih metalingvističkih kompetencija. 


\section{Literatura}

Apperly, I. A. \& E. J. Robinson (2002). „Five-year-olds' handling of reference and description in the domains of language and mental representation." Journal of Experimental Child Psychology 83, 53-75.

Bates, E. (1976). Language and Context: The Acquisition of Pragmatics. New York: Academic Press.

Berthoud-Papandropoulou, I. (1978). “An experimental study of children's ideas about language." U: A. Sinclair et al. (eds.), 55-64.

Bowey, J. A. \& W. E. Tunmer. (1984). "Word Awareness in Children.” U: Metalinguistic Awareness in Children: Theory, Research, and Implications, ed. by Tunmer, W. E., C. Pratt, and M. L. Herriman, 73-91. Berlin: SpringerVerlag.

Downing, J. \& P. Oliver (1974). The child's conception of "a word", Reading Research Quarterly 9, 568-582.

Edwards, H. T. \& A. G. Kirkpatrick. (1999). „Metalinguistic Awareness in Children: A Developmental Progression." Journal of Psycholinguistic Research, 28 (4), 313-329.

Ephratt, M. (1991). „Piaget's Nominal Realism From a Linguistic Point of View.“ Language Learning 41, 4, 555-598.

Francis, H. (1973). „Children's experience of reading and notions of units in language." British Journal of Educational Psychology 43, 17-23.

Gombert, J. E. 1997. "Metalinguistic Development in First-Language Acquisition." U: Van Lier L., Corson D. (ed.), Encyclopedia of Language and Education, tom 6. Dordrecht: Springer, 43-52.

Holden, M. \& McGinitie, W. (1972). “Children's conceptions of word boundaries in speech and print." Journal of Educational Psychology 6, 551-557.

Homer, B. \& Olson D. R. (1999). „Literacy and Children's Conception of Words.“ Written Language \& Literacy 2, 1, 113-140.

Kamawar, D. \& D. R. Olson. (1999). „Children's Representational Theory of Language: The Problem of Opaque Contexts." Cognitive Development 14, 531-548.

Karmiloff-Smith A., Grant J., Sims K., Jones M.C., Cuckle P. (1996). „Rethinking metalinguistic awareness: Representing and accessing knowledge about what counts as a word." Cognition 58, 197-219.

Kodžopeljić, J. (1997). "Svest o rečima kao faktor usvajanja čitanja.” Psihologija, 3, 231-240. 
Kurvers, J. \& H. Uri. (2006). "Metalexical awareness: development, methodology or written language? A cross-linguistic comparison." Journal of Psycholinguistic Research, 35 (4), 353-367.

Kurvers, J., R. van Hout i T. Vallen. (2006). "Literacy and Word Boundaries." U: N. Faux (Ed.), Low-Educated Second Language and Literacy Acquisition Research, Policy, and Practice. Proceedings of the Second Annual Forum. Richmond, Virginia: The Literacy Institute at Virginia Commonwealth University, 45-64.

Law, J. M. \& P. Ghesquière. (2017). "Early development and predictors of morphological awareness: Disentangling the impact of decoding skills and phonological awareness." Research in Developmental Disabilities 67, 47-59.

Lundberg, I. (1978). "Aspects of linguistic awareness related to reading.” U: A. Sinclair, R. Jarvella, \& W. Levelt (Eds.), The child's conception of language. New York: Springer-Verlag, 83-96.

Lundberg, I., \& Torneus, M. (1978). „Nonreaders' awareness of the basic relationship between spoken and written words." Journal of Experimental Child Psychology 25, 404-412.

Moskovljević Popović, J. i Plut, D. (2011). „Razvoj sposobnosti za samopro-

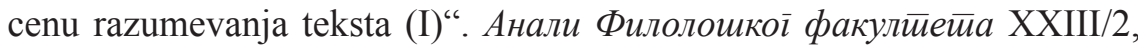
297-309.

Onderdelinden, L., I. van de Craats i J. Kurvers. (2009). "Word Concept of Illiterates and Low-literates: Worlds Apart?". Dostupno na: https://dspace. library.uu.nl/bitstream/handle/1874/297101/bookpart.pdf. [20. 4. 2017.]

Owens, R. E., Jr. (1996). Language development, 4th ed. Boston: Allyn \& Bacon.

Papandropoulou, I. \& A. Sinclair (1974). ,What is a Word? Experimental Study of Children's Ideas on Grammar." Human Development 17, 241-258.

Piaget, J. (1951). The Child's Conception of the World. London: Routledge.

Ravid, D. and L. Tolchinsky. (2002). „Developing linguistic literacy: A comprehensive model.“ Journal of Child Language 29, 417-447.

Reder F., Marec-Breton N., Gombert J.-E. \& Demont E. (2013). "Second-language learners' advantage in metalinguistic awareness: A question of languages' characteristics." British Journal of Educational Psychology 83, 686-702.

Roth, F.P., Speece, D. L., Cooper, D.H., De La Paz, S. (1996). „Unresolved Mysteries: How do Metalinguistic and Narrative Skills Connect with Early Reading?" The Journal of Special Education 30, 257-277.

Sharpe, D. \& P. D. Zelazo. (2002). „The foundations and development of metalinguistic knowledge.“" Journal of Child Language 29, 2, 484-488. 
Snow, C. E., M. S. Burns i P. Griffin. (1998). Preventing reading difficulties in young children. Washington, DC: National Academy Press.

de Sosir, F. (1989). Opšta lingvistika. Beograd: Nolit.

Tunmer, W. E. \& J. A. Bowey. (1984). "Metalinguistic Awareness and Reading Acquisition.” U: Tunmer, W. E., C. Pratt, and M. L. Herriman, eds. Berlin: Springer-Verlag, 144-168.

Tunmer, W. E. \& R. Grieve. (1984). „Syntactic awareness in children.“ U: W. E. Tunmer et al. (eds.), 92-104.

Tunmer, W. E. \& Herriman, M. (1984). „The development of metalinguistic awareness: A conceptual overview.“ U: Tunmer, W. E., C. Pratt, and M. L. Herriman, eds. Berlin: Springer-Verlag, 12-35.

Tunmer, W. E., C. Pratt, and M. L. Herriman, eds. (1984). Metalinguistic Awareness in Children: Theory, Research, and Implications. Berlin: Springer-Verlag.

Vigotski, L. (1996). Sabrana dela, tom II - Problemi opšte psihologije (Mišljenje i govor i Predavanja iz psihologije). Beograd: ZUNS.

Jasmina Moskovljević Popović

\section{Summary}

\section{ON DEVELOPMENT OF METALINGUISTIC AWARENESS - WORD AWARENESS}

Word awareness is considered to be one of the major components of metalinguistic awareness. The primary objective of this paper is to present and analyse the different approaches to the investigation of this phenomenon, as well as to review experimental findings about three aspects of word awareness development: development of awareness of word as a unit of language, development of awareness of the arbitrary nature of the lexical sign, and development of understanding of the "word" as a metalinguistic concept. Having in mind the results of previous research which suggests that literacy plays a significant role in enhancing one's metalinguistic knowledge, and thus one's word concept, special attention has been paid to the study of the nature of relationship between word awareness development and literacy acquisition and different approaches and solutions to this problem.

Key words: metalinguistic competences, word awareness development, literacy acquisition; pre-school and early school-age children 